\title{
Caracterização da utilização do BIM no Distrito Federal
}

\author{
Characterization of the use of Building Information \\ Modeling in the Distrito Federal, Brazil
}

\section{Felipe Valadares Faim Carmona Michele Tereza Marques Carvalho}

\section{Resumo}

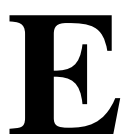

ste estudo visa caracterizar, de forma pioneira, a utilização do BIM por construtoras atuantes no Distrito Federal. O seu objetivo é a obtenção de dados regionalizados que, quando comparados aos de âmbito nacional e estrangeiros, possam retratar a real situação local dessa tecnologia. Sua repetição periódica e replicação em outras localidades podem identificar tendências e peculiaridades, cujo conhecimento pode ensejar medidas que auxiliem na difusão do BIM. Esta pesquisa se fundamentou nas respostas obtidas em questionários eletrônicos enviados por e-mail para profissionais da construção civil do Distrito Federal. Em parte dos dados, foi aplicado o Relative Importance Index para se ponderar as frequências e os valores das respostas. Os resultados indicam uma baixa implementação e a predominância de usos superficiais. Na discussão são exploradas possíveis relações e consequências entre a adoção e o uso da tecnologia, suas dificuldades de implantação, expectativas futuras e características dos profissionais entrevistados e suas empresas.

Palavras-chave: BIM. Uso do BIM. Distrito Federal.

\section{Abstract}

The objective of this study is to characterize, for the first time, the use of Building Information Modeling (BIM) by contractors in the Distrito Federal. The main aim is to obtain local data that, after comparing it with national and international data, may express the real situation of BIM in this area. Its periodic repetition and replication in other places may identify tendencies and peculiarities whose

Felipe Valadares Faim Carmona Universidade de Brasília Brasília - DF - Brasil

Michele Tereza Marques Carvalho

Universidade de Brasília Brasília - DF - Brasil

Recebido em 13/04/16 Aceito em 10/09/16 knowledge may result in actions that enhance the diffusion of BIM. This research was based on answers obtained from electronic questionnaires sent by email to local construction professionals. The Relative Importance Index was used in part of the data in order to consider the frequency of the answers and their values. The results indicate a low implementation level and mainly superficial uses. In the Discussion section, the possible relations and consequences between the adoption and use of technology, its implementation difficulties, future expectations and personal characteristics of the professionals interviewed and their companies are explored.

Keywords: BIM. Distrito Federal-Brazil. 


\section{Introdução}

O Building Information Modeling (BIM) pode ser definido como um método de trabalho que agrega procedimentos e informações relevantes a uma representação gráfica. Tido por muitos como uma ferramenta fundamental para o aumento da eficiência da construção civil, a sua adoção ainda não é plena em escala global e muito menos no Brasil, onde é a exceção, e não a regra.

Embora existam pesquisas que meçam nacionalmente a sua utilização e indiquem as principais dificuldades de implantação, os seus enfoques nacionais não permitem a regionalização dos dados. É possível, e até provável, que existam regiões em que a tecnologia esteja muito mais desenvolvida do que em outras, ou que os problemas enfrentados em determinados locais sejam completamente diferentes daqueles presentes em outros. No entanto, com os dados atualmente disponíveis, a identificação dessas discrepâncias é impossível. Em um país marcado por desigualdades, dados generalistas não bastam e deixam lacunas que devem ser preenchidas para que se entenda realmente em quais locais e de que forma a tecnologia está sendo utilizada. Este estudo é um pequeno passo nesse sentido, uma tentativa de caracterizar regionalmente a utilização do BIM. Buscou-se retratar a sua situação no Distrito Federal e compará-la aos dados nacionais e internacionais disponíveis.

A principal contribuição desejada com este trabalho é dar início a uma coleta de informações que, se repetida periodicamente e replicada em outras regiões, pode explicitar diferenças importantes e subsidiar comparações e entendimentos mais precisos sobre os diversos estágios do BIM no País. A compreensão de peculiaridades locais pode ser importante para a superação de barreiras que dificultam disseminação da tecnologia e interessa, portanto, a todos os personagens com ela envolvidos, sejam acadêmicos, profissionais da construção civil e entidades governamentais.

Por meio de um questionário estruturado, investigou-se a adoção do BIM por dezesseis das principais empresas construtoras atuantes no mercado imobiliário residencial e comercial do Distrito Federal e as maiores dificuldades enfrentadas durante a sua implantação (ou que acabaram por impossibilitá-la). Não foram abordados aspectos relativos a legislações e normatizações brasileiras, que, por si sós, constituem tema relevante para outros estudos.

\section{BIM}

A sigla BIM é muitas vezes utilizada para designar, equivocadamente, o nome ou categoria de softwares de modelagem tridimensional. Na verdade, essas três letras carregam um significado muito maior, elas representam toda uma metodologia de trabalho, que notadamente abarca uma extensa infraestrutura tecnológica, mas sem nela se encerrar. Os programas e computadores são os meios, as ferramentas, mas a real força do BIM está na informação, interação, colaboração e organização. Consonante e partícipe da revolução digital, essa tecnologia globaliza o desenvolvimento de projetos; múltiplos colaboradores podem trabalhar em uma mesma base desde estágios iniciais, o que pode resultar em produtos mais harmônicos e eficientes. Nesse sentido, encontram-se definições como a de Succar (2010), para quem BIM é o conjunto de políticas de interação, processos e tecnologia, que gera uma metodologia para o gerenciamento de projetos $\mathrm{e}$ dados em formato digital que possam cobrir todo o ciclo de vida da edificação. Khemlani, no BIM Handbook (EASTMAN et al., 2011), salienta que é importante compreender que o BIM não é só uma mudança de tecnologia, é uma mudança de processos. Nessa mesma obra, os autores argumentam que a indústria de desenvolvimento de software tem utilizado exaustivamente o termo para definir muitas das funcionalidades de seus produtos, o que pode causar confusão sobre o seu correto significado. Para esclarecê-lo, foi criada uma lista com exemplos do que não é BIM, citando inclusive os modelos criados com o programa SketchUp ${ }^{\circledR}$, que, segundo eles, é ótimo para rápidos desenhos esquemáticos, mas suas representações não trazem nenhuma informação além da aparência e das dimensões dos objetos retratados (EASTMAN et al., 2011).

\section{Usos do BIM}

No estudo de caso da aplicação do BIM na construção do Walt Disney Concert Hall (HAYMAKER; FISCHER, 2001), os autores listam os desafios e os benefícios da aplicação de um modelo 4D, que engloba informações do planejamento. Mesmo se tratando de um artigo de 2001, muitas das situações descritas ainda são pertinentes e o grau de imersão dos múltiplos participantes na metodologia segue sem paralelo no dia a dia da construção civil brasileira. Além da tradicional compatibilização de projetos e remoção de conflitos, destacam-se os seguintes pontos positivos identificados pelos autores: 
(a) análise do cronograma: mescla do modelo tridimensional com o planejamento da construção, criando-se o 4D. As restrições, as oportunidades e os conflitos temporais são mais facilmente visualizados, o que permite o aprimoramento do cronograma;

(b) facilidade de comunicação: informações são transmitidas com maior velocidade para novos integrantes, reuniões ou grupos que não participam do cotidiano das obras, como os clientes; e

(c) sinergia da equipe: em um setor cada vez mais especializado (e fragmentado), a criação de um espírito de equipe entre os diversos empreiteiros é um fator crítico para a garantia de prazo, segurança e qualidade. Segundo os autores, não era raro que, após o término das reuniões, os subempreiteiros continuassem a discutir por mais de uma hora, por conta própria, soluções para problemas e as melhores maneiras de se executar determinada atividade.

Também são citados no livro BIM Handbook (EASTMAN et al., 2011) os seguintes usos para a tecnologia:

(a) colaboração de projetistas de múltiplas disciplinas em um estágio muito anterior do que em projetos tradicionais;

(b) extração, em qualquer estágio de desenvolvimento do projeto, de estimativas de custos e quantitativos;

(c) análise em tempo real de propostas de alteração de projetos;

(d) maior facilidade de aplicação de técnicas da lean construction (construção enxuta);

(e) geração, a qualquer momento, de plantas, cortes ou quaisquer outras representações 2D; e

(f) facilita a gestão do uso e manutenção da edificação.

Embora incomum, a aplicação dessa tecnologia na segurança do trabalho pode ser útil, conforme exemplificado por Biotto, Formoso e Isatto (2013). Em um estudo de caso, a aplicação de modelos BIM 4D permitiu a identificação de uma situação de risco para os operários durante a simulação da execução da fachada. Nesse mesmo trabalho, a tecnologia foi aplicada para auxiliar no planejamento de longo prazo, simulando alternativas de plano de ataque, leiaute de canteiro e escolha de equipamentos.

$\mathrm{Na}$ Tabela 1 foram reunidos os principais usos do BIM apontados em duas pesquisas.

\section{Estágios de adoção do BIM}

De acordo com Rekola, Kojima e Mäkeläinen (2010), está cada vez mais nítido para pesquisadores e usuários que as mudanças trazidas pelo BIM não se limitam, nem se bastam, a softwares e tecnologias. Elas devem necessariamente passar por uma remodelagem de práticas intra e interorganizacionais, que envolvem redefinições de processos, cargos e funções. Os autores concluem que muitos dos problemas que dificultam a aplicação do BIM são criados porque as pessoas usam tecnologias novas, mas mantêm processos antigos.

Essa concepção de alteração de processos foi demonstrada há mais de quinze anos por Grover, em seu artigo de 1998. Foram identificadas fortes evidências de que o ganho de produtividade oriundo de novas tecnologias, principalmente naquelas colaborativas, só é percebido após mudanças nos processos (GROVER et al., 1998).

Em uma pesquisa com usuários finlandeses, a grande maioria $(>80 \%)$ concorda que foram necessárias mudanças no fluxo de trabalho, práticas e procedimentos (FINNE;HAKKARAINEN; MALLESON, 2013). $\mathrm{O}$ que converge para o conceito de que o BIM é mais do que uma simples aplicação de software.

Tabela 1 - Principais usos do BIM

\begin{tabular}{c|l|c|l|c}
\hline Fonte & \multicolumn{2}{|c|}{ PINI (2013) } & \multicolumn{2}{c}{ Langar e Pearce (2014) } \\
\hline País/Região & \multicolumn{1}{|c|}{ Brasil } & $\%$ & \multicolumn{1}{c}{ Sudeste EUA } & \% \\
\hline \multirow{5}{*}{ Principais } & - Projetos & & - Visualização & $83 \%$ \\
usos & - Levantamentos quantitativos & $60 \%$ & - Apresentações iniciais & $80 \%$ \\
& - Compatibilização de projetos & $50 \%$ & - Projetos executivos & $68 \%$ \\
& - Orçamentos & $35 \%$ & - - Comálise construtiva & $63 \%$ \\
& - Cronograma & $20 \%$ & - Projetos de reforma & $58 \%$ \\
& & & - Projetos de sustentabilidade & $50 \%$ \\
\hline
\end{tabular}


Para se entender melhor os estágios de aplicação da tecnologia, recorre-se à divisão em cinco níveis proposta por Succar (2010):

(a) Pré-BIM: grande dependência de representações $2 \mathrm{D}$. Podem até existir representações 3D, mas elas não possuem informações atreladas e são modeladas com base em documentos bidimensionais. Quantitativos, estimativas de custos e especificações não podem ser automaticamente extraídos do modelo. O fluxo de trabalho é linear e sem interação entre diferentes disciplinas;

(b) Estágio 1: a utilização do BIM se inicia com a criação de uma modelagem 3D paramétrica unidisciplinar. O modelo é, normalmente, usado para automatizar a geração e coordenação de documentos 2D e propiciar a visualização em 3D. Dados básicos, como o volume de concreto, podem ser exportados. Não há alterações no fluxo de trabalho em comparação com o estágio anterior;

(c) Estágio 2: há o início de colaboração de outros projetistas. Pode-se unir, por exemplo, as modelagens estruturais e arquitetônicas. Inicia-se sutilmente a modificação do fluxo de trabalho, frentes antes isoladas são visualizadas conjuntamente em um mesmo modelo;

(d) Estágio 3: o projeto finalmente se torna multidisciplinar. Servidores centrais ou nuvens de dados permitem que vários profissionais trabalhem simultaneamente em uma mesma base. O fluxo de trabalho não é mais linear, mas sim espiral, girando em torno de um banco de dados unificado e compartilhado. Mesmo em etapas iniciais de desenvolvimento já são possíveis análises mais complexas. Pode-se contemplar o ciclo de vida do projeto e princípios da lean construction e business intelligence. Não há mais etapas de desenvolvimento de projeto, ele passa a ser contínuo, fluído; e

(e) Entrega integrada de projetos: este estágio possui diferentes nomes: Integrated Project Delivery (IPD); Fully Integrated and Automated Technology (FIATECH); Integrated Design Solutions; e nD (o "n" representa o avanço nas dimensões de projeto, chegando-se à completa integralização: 2D, 3D, 4D, 5D, ..., nD). É o resultado de um fluxo de trabalho contínuo e evolutivo, altamente integrado e conectado a diversos bancos de dados em tempo real, agregando informações de todas as perspectivas possíveis.

\section{Produtividade da construção civil}

Em uma de suas apresentações sobre o projeto KanBIM, Sacks (2011) compara a velocidade de construção de prédios entre os anos de 1929 e 2007. Percebe-se claramente que as obras mais antigas evoluíam muito mais rapidamente do que as atuais. Essa constatação é reforçada por autores como Teicholz (EASTMAN et al., 2011), cuja pesquisa citada no BIM Handbook demonstra que a atual produtividade da construção civil é menor do que aquelas obtidas na década de 60.

De acordo com Lindblad (2013), o BIM foi considerado por muitos como a solução para a baixa produtividade histórica da indústria da construção civil quando comparada às outras indústrias. Essa, certamente, é uma das maiores esperanças dos incentivadores do BIM. O governo britânico, por exemplo, espera que até 2025 a tecnologia ajude a reduzir em até $50 \%$ do tempo total desde o início de um projeto até a sua entrega completa (MALLESON, 2015).

Há, no entanto, divergências sobre o real impacto dessa tecnologia na produtividade dos projetistas. Em pesquisa com usuários finlandeses, apenas $22 \%$ afirmaram que o BIM reduziu o tempo necessário para as entregas, $24 \%$ relataram maior eficiência financeira e $27 \%$ maior lucratividade nos projetos. Mesmo assim, só $4 \%$ prefeririam não ter adotado o BIM (FINNE; HAKKARAINEN; MALLESON, 2013).

Em uma ampla revisão bibliográfica, Miettinen e Paavola (2014) identificam quatro elementos do que eles chamam de BIM utopia. Eles representam as vantagens que seriam obtidas com a implantação plena da tecnologia. São os seguintes:

(a) todos os dados necessários para projetar e construir determinado empreendimento estarão inclusos em um único modelo BIM, ou facilmente acessíveis em banco de dados ou repositórios compartilhados;

(b) interoperatividade de dados provenientes de múltiplas plataformas, propiciando maneiras integradas de trabalho;

(c) o BIM será mantido e utilizado durante toda a vida útil do projeto (edificação); e

(d) o BIM aumentará consideravelmente a eficiência e a produtividade da indústria da construção.

Cada um desses elementos é analisado com base em múltiplas publicações. Em relação à eficiência e à produtividade, os autores afirmam que há muito pouca evidência empírica que mostre 
alguma correlação entre o aumento dessas e o BIM. Há dificuldades em se obter uma mensuração adequada dessa relação, pois é difícil isolar o BIM de outros fatores que contribuem para o sucesso de um projeto. Seria, talvez, muito cedo para se determinar o real valor da tecnologia, pois a indústria ainda está em fase inicial de adoção. O seu potencial é, no entanto, muito evidente. Para os autores, a promoção dessas utópicas promessas é uma maneira de atrair a atenção, e consequente financiamento de apoiadores, e estimular a adoção da causa em agendas técnicas e políticas (MIETTINEN; PAAVOLA, 2014).

\section{Implantação do BIM ao redor do mundo e no Brasil}

$\mathrm{Na}$ Tabela 2 foram agrupados os dados de implantação do BIM encontrados em múltiplas fontes da literatura.

Dentre os dados da Tabela 2, destaca-se a evolução da adoção da tecnologia por parte dos britânicos e americanos. No Reino Unido a adoção crescente desde 2010 foi, muito provavelmente, impulsionada pela medida governamental que obrigará a utilização do BIM em seus projetos a partir de 2016 (MALLESON, 2015). No caso americano percebe-se uma aparente divergência entre os dados da McGraw-Hill (2012) e os de Langar e Pearce (2014). A velocíssima evolução retratada pela editora nova-iorquina reflete, segundo os autores da pesquisa, dados da indústria da construção como um todo, enquanto os de Langar e Pearce são restritos às empresas de arquitetura do sudeste dos Estados Unidos. A redução do campo amostral foi necessária, segundo esses autores, para mostrar que a adoção do BIM pode ser impactada pela capacidade de investimento dessas empresas, em sua maioria pequenas e com menos de dez funcionários. Dados da McGraw-Hill também apontam nesse sentido, indicando que o porte da empresa é extremamente significativo na adoção da tecnologia, conforme pode ser visto na Tabela 3 .

As conclusões de Langar e Pearce (2014) são compatíveis com essa percepção. Os autores notaram que o porte da organização tem maior impacto na adoção do BIM do que a experiência (anos de existência) das empresas.

Os dados apresentados pela McGraw-Hill (2012) também foram segmentados em regiões, dividindo os Estados Unidos em quatro, como pode ser visto na Tabela 4.

Tabela 2 - Utilização do BIM em múltiplas localidades

\begin{tabular}{c|c|c|c|c|c|c|c|c|c|c}
\hline Fonte & \multicolumn{2}{|c|}{$\begin{array}{c}\text { Malleson } \\
\mathbf{( 2 0 1 5 )}\end{array}$} & $\begin{array}{c}\text { Finne, } \\
\text { Hakkaraien e } \\
\text { Malleson (2013) }\end{array}$ & \multicolumn{3}{|c|}{ McGraw-Hill (2012) } & $\begin{array}{c}\text { Langar e } \\
\text { Pearce } \\
(2014)\end{array}$ & $\begin{array}{c}\text { Pini } \\
(\mathbf{2 0 1 3})\end{array}$ \\
\hline País/Região & Reino Unido & Finlân-dia & \multicolumn{2}{|c|}{ Canadá } & \multicolumn{2}{|c|}{ EUA } & $\begin{array}{c}\text { Sudeste } \\
\text { EUA }\end{array}$ & Brasil \\
\hline Ano (pesquisa) & 2010 & 2014 & 2013 & 2009 & 2012 & 2007 & 2009 & 2012 & 2014 & 2013 \\
\hline Utilizam o BIM & $13 \%$ & $48 \%$ & $65 \%$ & $49 \%$ & $72 \%$ & $28 \%$ & $49 \%$ & $71 \%$ & $42 \%$ & $38 \%$ \\
\hline $\begin{array}{c}\text { Apenas conhecem } \\
\text { o BIM }\end{array}$ & $45 \%$ & $48 \%$ & $22 \%$ & --- & --- & --- & --- & --- & --- & -- \\
\hline $\begin{array}{c}\text { Desconhecem } \\
\text { BIM }\end{array}$ & $43 \%$ & $5 \%$ & $13 \%$ & --- & --- & --- & --- & --- & --- & -- \\
\hline
\end{tabular}

Tabela 3 - Utilização do BIM nos Estados Unidos de acordo com o porte da empresa

\begin{tabular}{c|c}
\hline Porte das empresas & Percentual de adoção do BIM (2012) \\
\hline Pequenas & $49 \%$ \\
Pequenas a médias & $76 \%$ \\
Médias a grandes & $86 \%$ \\
Grandes & $91 \%$ \\
\hline
\end{tabular}

Fonte: McGraw-Hill (2012).

Tabela 4 - Utilização do BIM em regiões dos Estados Unidos

\begin{tabular}{c|c|c|c|c|c|c|c}
\hline \multicolumn{8}{c}{ Regiões dos Estados Unidos } \\
\hline \multicolumn{2}{c|}{ Oeste } & \multicolumn{2}{c}{ Meio-Oeste } & \multicolumn{2}{c}{ Nordeste } & \multicolumn{2}{c}{ Sul } \\
\hline 2009 & 2012 & 2009 & 2012 & 2009 & 2012 & 2009 & 2012 \\
$56 \%$ & $77 \%$ & $52 \%$ & $73 \%$ & $38 \%$ & $66 \%$ & $45 \%$ & $68 \%$ \\
\hline
\end{tabular}

Fonte: McGraw-Hill (2012). 
Com essa subdivisão, fica claro que há significativas diferenças, até $11 \%$, na adoção do BIM conforme a região analisada. Certamente essas divergências se tornariam ainda mais nítidas caso houvesse uma menor aglutinação de regiões.

Os dados brasileiros, oriundos de uma pesquisa on-line conduzida em 2013, apontam que a adoção nacional é a menor dentre os países analisados. Há, no entanto, uma expectativa de avanço do BIM, tendo em vista a informação de que mais de $90 \%$ dos entrevistados pretendem utilizá-lo nos próximos cinco anos (PINI, 2013).

\section{Dificuldades enfrentadas na implantação}

As principais dificuldades apontadas pelos usuários na literatura pesquisada foram reunidas na Tabela 5.

\section{Plano Brasil Maior}

Em 2011 o governo brasileiro lançou o Plano Brasil Maior (BRASIL, 2011), cujo principal objetivo era aumentar, até 2014 , a competitividade da indústria nacional em diversas frentes de atuação. Na construção civil, um dos objetivos era: "Apoiar a intensificação do uso de TI aplicada à construção e a implantação do sistema de classificação da informação da construção normas BIM (NBR).” (CONSELHO..., 2013).

Esse objetivo se desdobra em três medidas, a saber:

(a) modelar e implantar a biblioteca de componentes da construção civil, disponibilizando a biblioteca em portal da internet com acesso público e gratuito;

(b) implantar a tecnologia BIM no sistema de obras do Exército; e

(c) difundir e complementar a normalização brasileira para o BIM.

De acordo com o Relatório de Acompanhamento das Agendas Estratégicas Setoriais, de outubro de 2014 (AGÊNCIA..., 2014), todas essas medidas estavam dentro dos prazos planejados. No entanto, as informações contidas no próprio documento apontam que nenhuma delas estava completamente implementada, a menos de três meses do final do ano. A sétima etapa da norma NBR 15965 (que apresenta a estrutura de classificação das informações para aplicação em BIM), por exemplo, só foi publicada em dezembro de 2015 (ABNT, 2015).

Quando se compara a ação governamental brasileira a outras, notadamente à britânica, ela soa extremamente genérica e simplista. As três medidas propostas são indubitavelmente importantes, mas não são suficientes para transformar o BIM em padrão nacional. A dificuldade em se obter dados desse programa é reflexo de seu esvaziamento, ou até mesmo abandono. Aparentemente o BIM ainda não é uma prioridade governamental. Não há, por exemplo, nenhum prazo estabelecido para que projetos contratados pelo governo utilizem a tecnologia. Essa negligência é lastimável, pois, como demonstrado na pesquisa da NBS (MALLESON, 2015), o governo pode ser protagonista no processo de difusão nacional da tecnologia.

Tabela 5 - Principais dificuldades de implantação do BIM

\begin{tabular}{|c|c|c|c|c|}
\hline \multirow{2}{*}{$\begin{array}{c}\text { Fonte } \\
\text { País/Região } \\
\end{array}$} & \multicolumn{2}{|l|}{ MALLESON, 2015} & \multicolumn{2}{|l|}{ PINI, 2013} \\
\hline & Reino Unido & & Brasil & \\
\hline $\begin{array}{c}\text { Principais } \\
\text { dificuldades } \\
\text { de } \\
\text { implantação }\end{array}$ & $\begin{array}{l}\text { - Falta de mão de obra interna } \\
\text { especializada } \\
\text { - Falta de treinamento } \\
\text { - Clientes não demandam a } \\
\text { tecnologia } \\
\text { - Custos } \\
\text { - Falta de tempo para se dedicar a } \\
\text { novas tecnologias } \\
\text { - Os projetos nos quais trabalham } \\
\text { são muito pequenos } \\
\text {-Falta de padronização de } \\
\text { ferramentas e protocolos }\end{array}$ & $\begin{array}{l}74 \% \\
67 \% \\
63 \% \\
56 \% \\
51 \% \\
43 \% \\
41 \%\end{array}$ & $\begin{array}{l}\text { - Alto custo de aquisição } \\
\text { - Alto custo de investimento em } \\
\text { treinamento } \\
\text { - Problemas com projetistas } \\
\text { colaboradores } \\
\text { - Falta de tempo } \\
\text { - Clientes não valorizam } \\
\text { - Falta de famílias de componentes } \\
\text { - Não vê vantagens imediatas }\end{array}$ & $\begin{array}{l}50 \% \\
40 \% \\
40 \% \\
25 \% \\
20 \% \\
20 \% \\
10 \%\end{array}$ \\
\hline
\end{tabular}

390 Carmona, F. V. F.; Carvalho, M. T. M. 
Figura 1 - Fluxograma do questionário

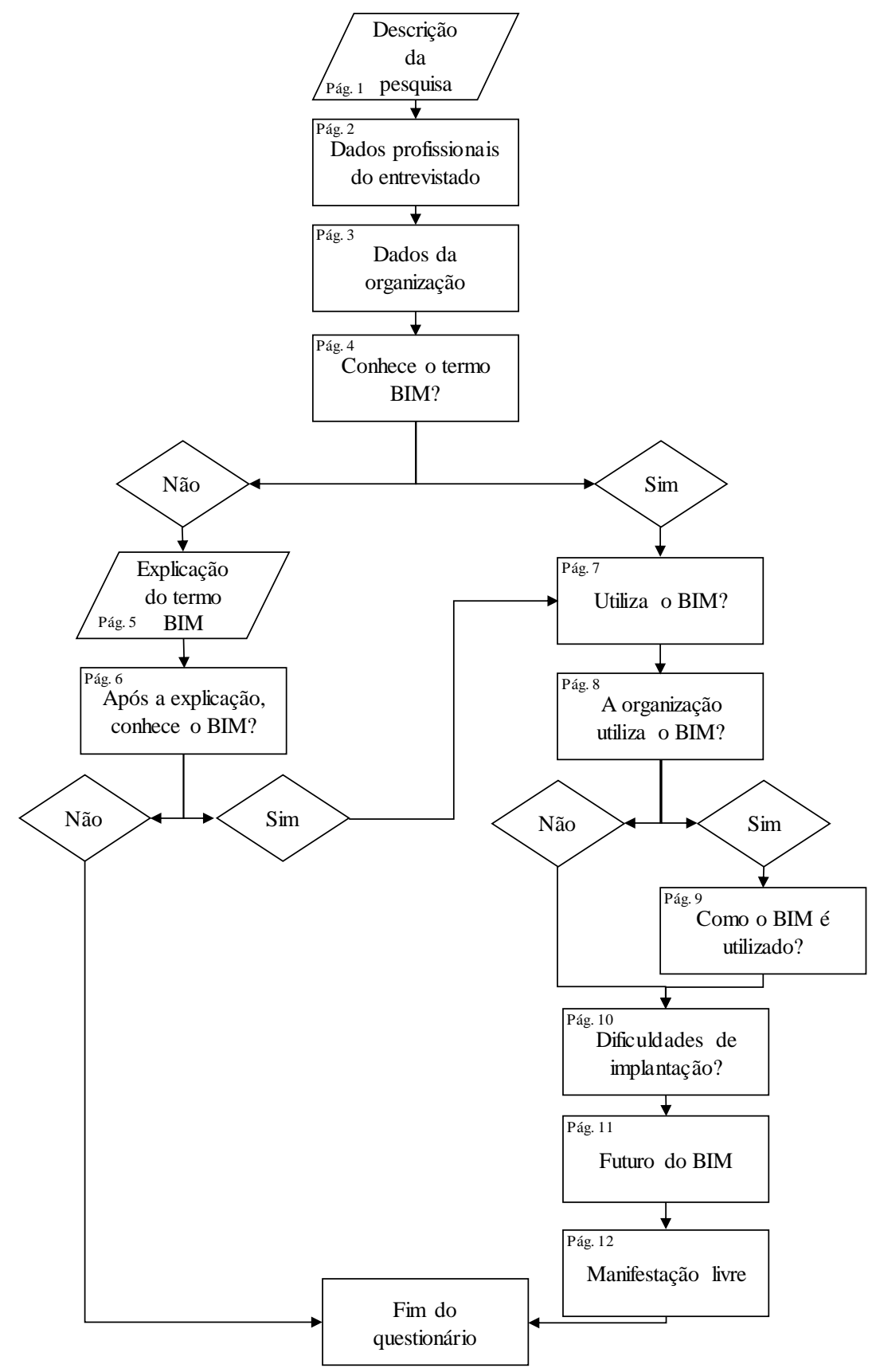

\section{Método de pesquisa}

Para verificar a adoção e qualificar a utilização do BIM no Distrito Federal foram enviados questionários estruturados para sessenta e três profissionais da construção civil do Distrito Federal, distribuídos em dezesseis organizações e quinze projetos diferentes. Os entrevistados figuram na lista de clientes de uma consultoria de planejamento que atua nas principais empresas do setor.
Para aumentar a quantidade de respostas e obter informações imparciais, os questionários foram confeccionados de modo a garantir a impossibilidade de identificação do usuário ou organização. Utilizou-se a plataforma Google Forms ${ }^{\circledR}$ devido à sua facilidade de criação, formatação, controle de respostas e gratuidade. O link para os questionários foi enviado em e-mails individuais que continham uma breve explicação sobre a pesquisa, seus objetivos e a estimativa de tempo de preenchimento, sete minutos. O fluxograma do questionário pode ser visto na Figura 1. 
Dentre os dados coletados estão informações profissionais (cargo ocupado, área de formação, experiência profissional, etc.) e da organização (quantidade de funcionários, faturamento, área de atuação, etc.). Eles propiciam a sua correlação com as respostas e podem apontar tendências. Busca-se, por exemplo, analisar se as dificuldades das pequenas empresas são as mesmas que as das grandes.

Em seguida averiguou-se o conhecimento do termo BIM pelo entrevistando, seus usos correntes, se a sua aplicação já rendeu resultados e quais foram (ou são) os principais problemas durante a sua implantação.

As dez dificuldades listadas no questionário foram coletadas na literatura e em conversas com usuários da tecnologia. Os entrevistados atribuíram valores de 0 (Não prejudicou) a 3 (Prejudicou muito) para as seguintes situações:

(a) a metodologia BIM não era suficientemente desenvolvida no início do projeto;

(b) desconhecimento ou falta de informação sobre o BIM;

(c) os líderes da organização ou projeto têm pouco conhecimento ou não dão importância ao BIM;

(d) o BIM ainda não é importante (ou não é demandado) para o mercado;

(e) falta de mão de obra interna especializada;

(f) os arquitetos ou projetistas colaboradores externos não utilizam BIM;

(g) complexidade do software;

(h) dificuldade de coordenação das diversas frentes de projeto e etapas envolvidas;

(i) o valor das licenças dos softwares; e

(j) o custo da infraestrutura de informática necessária.

Por último, perguntou-se aos entrevistados como eles se veem utilizando a tecnologia nos próximos cinco anos; se eles acreditam que o BIM substituirá o processo de projeto em 2D; e em quanto tempo eles acreditam que o BIM se tonará padrão de mercado.

As respostas foram computadas em uma planilha eletrônica e, em parte de sua análise, foi utilizado o Relative Importance Index (RII), conforme definido por Assaf (ASSAF; AL-KHALIL; ALHAZMI, 1995) e aplicado em estudos cuja metodologia de pesquisa foi semelhante à deste (ASSAF; AL-HEJJI, 2006; KAZAZ; ULUBEYLI;
TUNCBILEKLI, 2012). O índice pondera a importância de cada uma das dificuldades de acordo com a frequência das respostas e os pesos a elas atribuídos. Sua fórmula, adaptada para a realidade deste estudo, é a indicada na Equação 1:

$R I I=\frac{\sum_{i=1}^{4} a_{i} \cdot x_{i}}{\sum_{i=1}^{4} x_{i}}$

Eq. 1

Onde:

$a_{i}$ é o peso de cada uma das respostas (0 - Não prejudicou; 1 - Prejudicou pouco; 2 - Prejudicou; e 3 - Prejudicou muito); e

$x_{i}$ é a frequência de cada uma delas.

\section{Resultados}

Dos 63 questionários enviados 22 foram respondidos, 35\%. Pesquisas semelhantes feitas em outros países obtiveram taxas de resposta entre $11 \%$ e $39 \%$ (GARDEZI et al., 2014) (LANGAR; PEARCE, 2014). As respostas foram coletadas durante nove dias, entre 15/06/2015 e 23/06/2015. Como pode ser visto na Figura 2, praticamente metade delas foi recebida no primeiro dia.

Houve problemas com os filtros de spam dos $e$ mails de uma organização, só resolvidos após a intervenção do responsável de TI e, em um dos projetos, o diretor solicitou que o questionário fosse previamente analisado por ele antes da liberação de envio para a sua equipe, o que reduziu o tempo disponível para preenchimento e entrega.

\section{Perfil dos respondentes}

Os dados dos respondentes foram agrupados em três gráficos, na Figura 3.

\section{Utilização e conhecimento do termo BIM}

O resultado obtido sobre a utilização e conhecimento do termo BIM pelos profissionais entrevistados foi agrupado à Tabela 2 apresentada na Revisão Bibliográfica, resultando na Tabela 6.

Faz-se necessário explicitar que sete dos respondentes não reconheceram inicialmente $o$ termo BIM, o que corresponde a $22 \%$ da amostra. No entanto, após uma sucinta explicação, cinco deles reconheceram, restando apenas dois respondentes (9\%) que desconheciam o termo BIM. Ambos são auxiliares de engenharia e integram grandes organizações. Eles não participaram das etapas posteriores do questionário. 
Figura 2 - Respostas recebidas

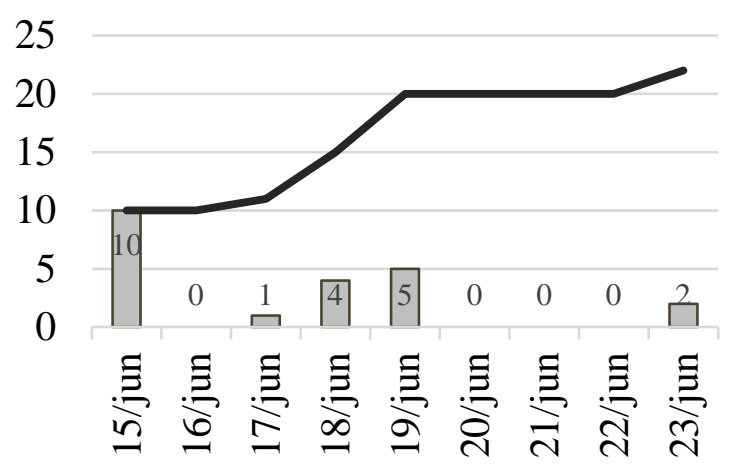

Figura 3 - Perfil dos respondentes

Cargo ocupado

15

10

5

0

Gerenciais Não Aux. de gerenciais eng.

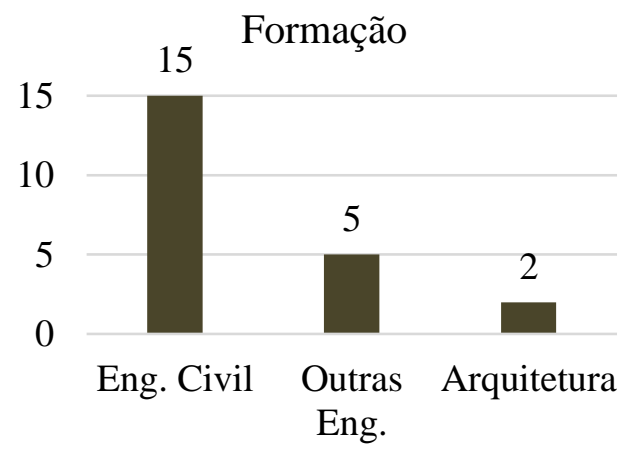

Eng.

\section{Experiência (anos)}

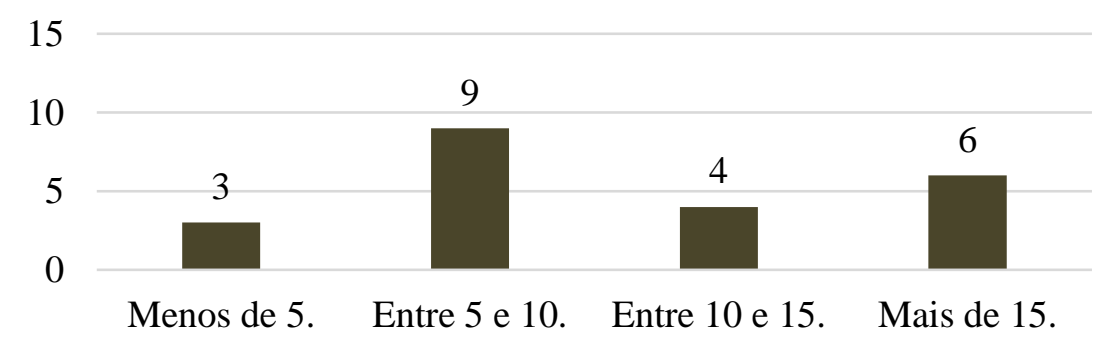

Tabela 6 - Utilização do BIM em múltiplas localidades, incluindo o Distrito Federal

\begin{tabular}{|c|c|c|c|c|c|c|c|c|c|c|c|}
\hline \multirow{2}{*}{$\begin{array}{c}\text { Fonte } \\
\text { País/ } \\
\text { Região }\end{array}$} & \multicolumn{2}{|c|}{$\begin{array}{c}\text { Malleson } \\
(2015)\end{array}$} & \multirow{2}{*}{$\begin{array}{c}\text { Finne, } \\
\text { Hakkar } \\
\text { ainen e } \\
\text { Malleso } \\
\text { n (2013) } \\
\begin{array}{c}\text { Finlân- } \\
\text { dia }\end{array}\end{array}$} & \multicolumn{5}{|c|}{ McGraw-Hill (2012) } & \multirow{2}{*}{$\begin{array}{c}\text { Langar e } \\
\text { Pearce } \\
(2014) \\
\begin{array}{c}\text { Sudeste } \\
\text { FUA }\end{array}\end{array}$} & \multirow{2}{*}{$\begin{array}{c}\text { Pini } \\
(2013) \\
\text { Brasil }\end{array}$} & \multirow{2}{*}{$\begin{array}{c}\text { Autores } \\
(2017)\end{array}$} \\
\hline & Reinc & Unido & & \multicolumn{2}{|c|}{ Canadá } & \multicolumn{3}{|c|}{ EUA } & & & \\
\hline $\begin{array}{c}\text { Ano } \\
\text { (pesquisa) }\end{array}$ & 2010 & 2014 & 2013 & 2009 & 2012 & 2007 & 2009 & 2012 & 2014 & 2013 & 2015 \\
\hline $\begin{array}{l}\text { Utilizam o } \\
\text { BIM }\end{array}$ & $13 \%$ & $48 \%$ & $65 \%$ & $49 \%$ & $72 \%$ & $28 \%$ & $49 \%$ & $71 \%$ & $42 \%$ & $38 \%$ & $36 \%$ \\
\hline $\begin{array}{c}\text { Apenas } \\
\text { conhecem o } \\
\text { BIM }\end{array}$ & $45 \%$ & $48 \%$ & $22 \%$ & --- & --- & --- & --- & --- & --- & --- & $55 \%$ \\
\hline $\begin{array}{c}\text { Desconhece } \\
\text { m o BIM }\end{array}$ & $43 \%$ & $5 \%$ & $13 \%$ & --- & --- & --- & --- & --- & --- & --- & $9 \%$ \\
\hline
\end{tabular}




\section{Utilização do BIM de acordo com o porte da empresa}

Apenas seis dos profissionais pesquisados $(27 \%)$ afirmaram que utilizam o BIM, outros dois (9\%) embora não o utilizem diretamente, trabalham em empresas que utilizam a tecnologia. As respostas foram segmentadas de acordo com o porte da organização, Figura 4.

O critério para definir o porte das organizações dos entrevistados foi a quantidade de empregados: pequena (20 a 99 empregados), média (100 a 499) e grande (mais de 500) (SERVIÇO..., 2015; VIVANCOS, 2001).

\section{Finalidade de uso do BIM}

Na Tabela 7 encontram-se as atividades nas quais os usuários utilizam o BIM. Ressalta-se que os usos mais avançados, como modelagens complexas (4D, 5D e 6D) e projeto colaborativo, foram indicados, cada um, por um único entrevistado.

\section{Descrição do uso do BIM}

Foi solicitado aos oito entrevistados que trabalham em organizações que utilizam o BIM que escolhessem a afirmação que mais se aproximasse da sua realidade. $\mathrm{O}$ resultado foi o apresentado na Tabela 8, que indica a ocorrência de cada uma das descrições de uso propostas.

\section{Resultado obtido com a utilização}

Conforme exposto na Figura 5, a utilização do BIM foi positiva para $37 \%$ dos usuários pesquisados; a utilização foi apenas parcialmente positiva para outros $50 \%$; e somente um usuário não percebeu ou não aferiu resultados positivos.

\section{Dificuldades de implantação}

Utilizou-se a Equação 1 para a obtenção do Relative Importance Index (RII) de cada uma das dificuldades propostas no questionário. Conforme proposto por Kazaz, Ulubeyli e Tuncbilekli (2012), as importâncias foram agrupadas de acordo com os intervalos de RII indicados na Tabela 9.

Figura 4 - Utilização do BIM por porte da empresa

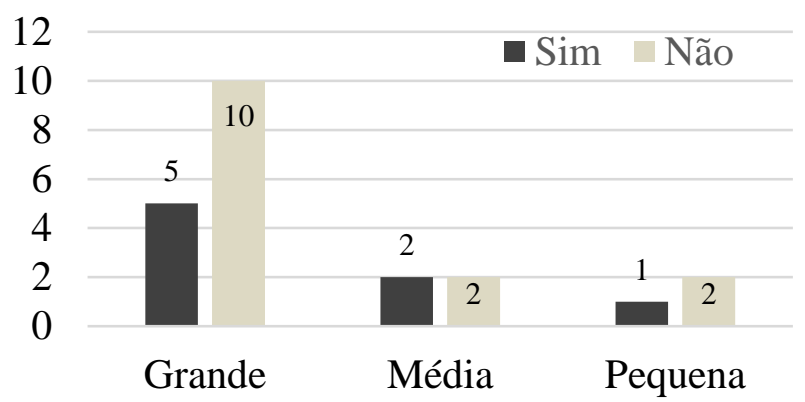

Tabela 7 - Principais usos do BIM

\begin{tabular}{|c|c|c|c|c|c|c|}
\hline Fonte & \multirow{2}{*}{\multicolumn{2}{|c|}{$\begin{array}{c}\text { Pini (2013) } \\
\text { Brasil }\end{array}$}} & \multirow{2}{*}{\multicolumn{2}{|c|}{$\begin{array}{c}\text { Langar e Pearce (2014) } \\
\text { Sudeste EUA }\end{array}$}} & \multirow{2}{*}{\multicolumn{2}{|c|}{$\frac{\text { Autores (2017) }}{\text { DF }}$}} \\
\hline País/Região & & & & & & \\
\hline $\begin{array}{l}\text { Principais } \\
\text { usos }\end{array}$ & $\begin{array}{l}\text { - Projetos } \\
\text { - Levantamentos } \\
\text { quantitativos } \\
\text { - Compatibilização } \\
\text { de projetos } \\
\text { - Orçamentos } \\
\text { - Cronograma }\end{array}$ & $\begin{array}{l}0 \% \\
60 \% \\
50 \% \\
35 \% \\
20 \%\end{array}$ & $\begin{array}{l}\text { - Visualização } \\
\text { - Apresentações iniciais } \\
\text { - Projetos executivos } \\
\text { - Análise construtiva } \\
\text { - Compatibilização de } \\
\text { projetos } \\
\text { - Projetos de reforma } \\
\text { - Projetos de } \\
\text { sustentabilidade }\end{array}$ & $\begin{array}{l}83 \% \\
80 \% \\
68 \% \\
63 \% \\
58 \% \\
50 \% \\
50 \%\end{array}$ & $\begin{array}{l}\text { - Remoção de } \\
\text { interferências } \\
\text { - Compatibilização } \\
\text { de projetos } \\
\text { - Modelagem 3D da } \\
\text { arquitetura e/ou } \\
\text { estrutura } \\
\text { - Levantamento } \\
\text { quantitativo } \\
\text { - Modelagem 4D, } \\
\text { 5D e 6D } \\
\text { - Projeto } \\
\text { colaborativo }\end{array}$ & $\begin{array}{l}50 \% \\
38 \% \\
13 \% \\
13 \%\end{array}$ \\
\hline
\end{tabular}

394 Carmona, F. V. F.; Carvalho, M. T. M. 


\begin{tabular}{|c|c|c|}
\hline Descrição & Ocorrência & $\%$ \\
\hline $\begin{array}{l}\text { Todas as atividades relativas ao BIM são internas. Todos os envolvidos são } \\
\text { funcionários da própria organização. }\end{array}$ & 0 & $0 \%$ \\
\hline $\begin{array}{l}\text { Parte dos serviços é executada por empresas terceirizadas (arquitetura e projeto de } \\
\text { instalações, por exemplo). } \\
\text { O controle e a gestão dos processos que envolvem o BIM são de responsabilidade } \\
\text { da própria organização. }\end{array}$ & 4 & $50 \%$ \\
\hline $\begin{array}{l}\text { Parte dos serviços é executada por empresas terceirizadas (arquitetura e projeto de } \\
\text { instalações, por exemplo). } \\
\text { O controle e a gestão dos processos que envolvem o BIM são de responsabilidade } \\
\text { de uma consultora/especialista externa, cujas atribuições incluem a conversão dos } \\
\text { projetos de CAD para BIM. } \\
\text { A análise gerencial segue sob responsabilidade da organização. }\end{array}$ & 1 & $13 \%$ \\
\hline $\begin{array}{l}\text { Todos os processos do BIM são terceirizados, a organização apenas usufrui dos } \\
\text { resultados. }\end{array}$ & 3 & $38 \%$ \\
\hline
\end{tabular}

Figura 5 - Obtenção de resultados positivos com o BIM

\section{O resultado da utilização do BIM foi positivo?}

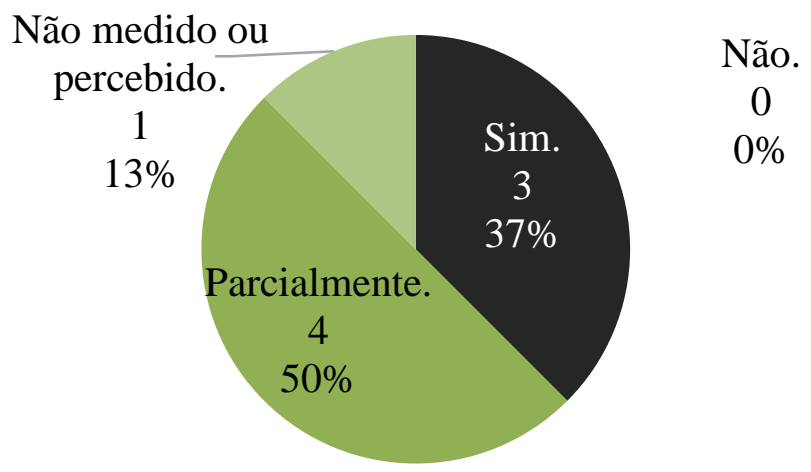

Tabela 9 - Intervalos de importância

\begin{tabular}{l|c}
\hline \multicolumn{1}{c|}{ Importância } & Intervalo RII \\
\hline Não prejudicou & $0,00-0,75$ \\
Prejudicou pouco & $0,76-1,50$ \\
Prejudicou & $1,51-2,25$ \\
Prejudicou muito & $2,26-3,00$ \\
\hline
\end{tabular}

Os impactos de cada uma das dificuldades de implantação do BIM e suas segmentações, de acordo com características dos respondentes e porte das empresas, foram reunidos na Tabela 10.

\section{Futuro do BIM}

Foram reunidas na Figura 6 as respostas das três perguntas que trataram do futuro do BIM.

Os três entrevistados que não o utilizam atualmente e não pretendem utilizá-lo em um futuro próximo têm características em comum: são engenheiros, não ocupam cargos gerenciais, têm entre cinco e dez anos de experiência e suas organizações não utilizam o BIM. Nenhum deles trabalha em empresas de grande porte.

\section{Discussão}

Embora o tamanho do grupo amostral possa parecer pequeno, ele reflete a reduzida quantidade de empreendimentos em andamento no Distrito Federal no período pesquisado. Dados da Companhia de Desenvolvimento do Planalto Central (Codeplan), órgão do Governo do Distrito Federal, indicam que nos anos 2014 e 2015 a construção civil no DF foi o subsetor com o pior desempenho econômico dentre todos os analisados 
(agropecuária, indústria e serviços), com retração de $4,75 \%$ em 2014 e $7,10 \%$ em 2015. A quantidade de empregos formais na construção em 2015 foi a menor da série histórica apresentada (2009-2015), indicando uma queda de aproximadamente $40 \%$ em relação ao melhor período, 2012 (COMPANHIA..., 2016).

\section{Adoção do BIM}

A adoção do BIM por construtoras no Distrito Federal, 36\%, foi muito próxima daquela encontrada pela Pini (2013) na pesquisa de âmbito nacional, $38 \%$ - o fato de essas pesquisas serem defasadas por dois anos e, mesmo assim, apresentarem resultados semelhantes será abordado mais adiante - e a menor dentre as localidades analisadas (Tabela 6).

A comparação com os dados estrangeiros pode ser, no entanto, uma fonte de inspiração, pois eles mostram que muito pode ser feito em um curto período. Analisando-se a evolução do BIM no Reino Unido em quatro anos nota-se que o desconhecimento da tecnologia caiu de $43 \%$ para $5 \%$, e o aumento da utilização foi de $13 \%$ para 48\% (MALLESON, 2015). A adoção no Distrito Federal estaria em uma posição intermediária entre os estágios britânicos de 2010 e 2014. O desconhecimento local do BIM, 9\%, foi inferior àquele apresentado pela pesquisa finlandesa, $13 \%$ (FINNE; HAKKARAINEN; MALLESON, 2013).

Tabela 10 - Impacto das dificuldades na implantação do BIM

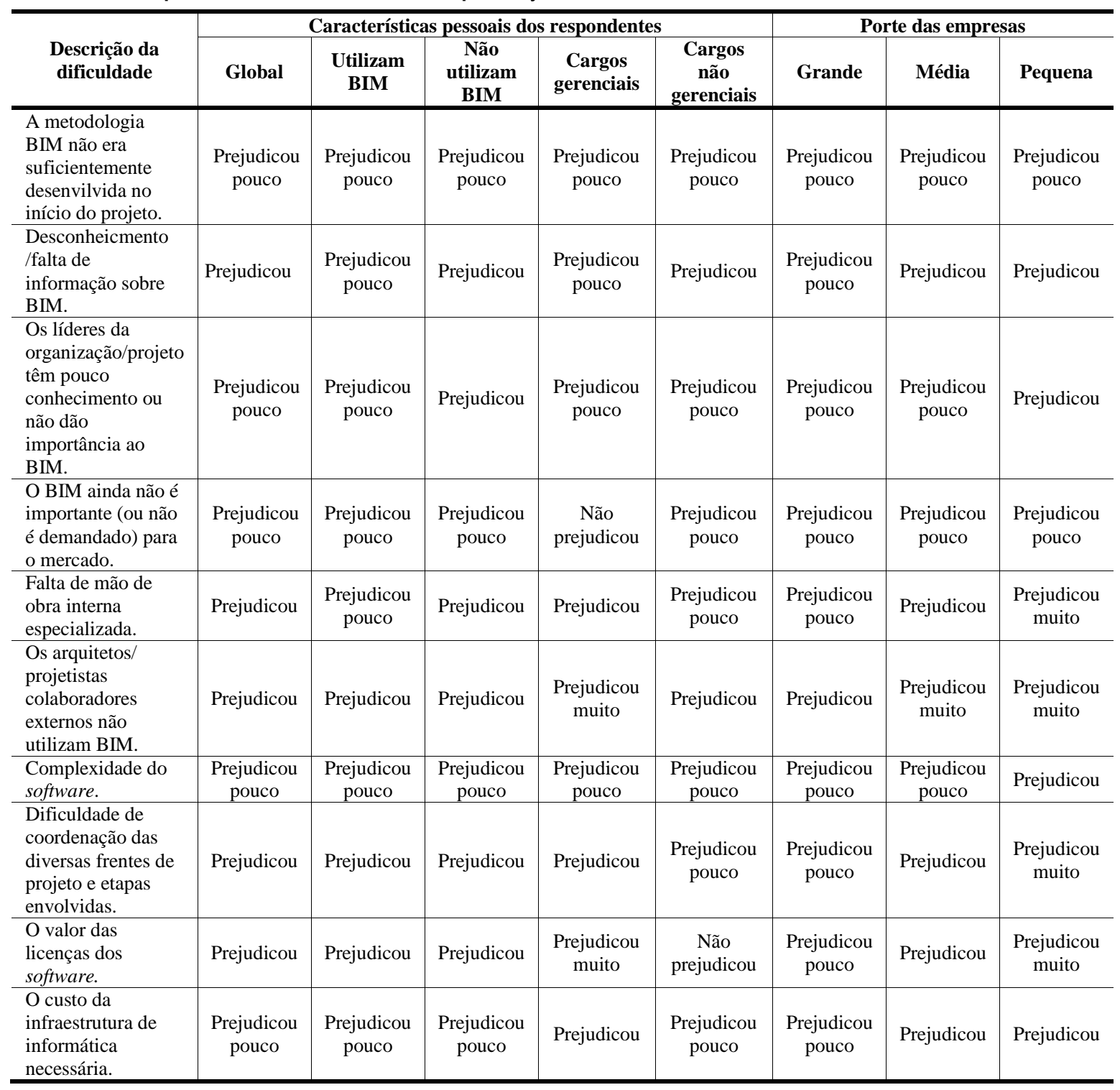




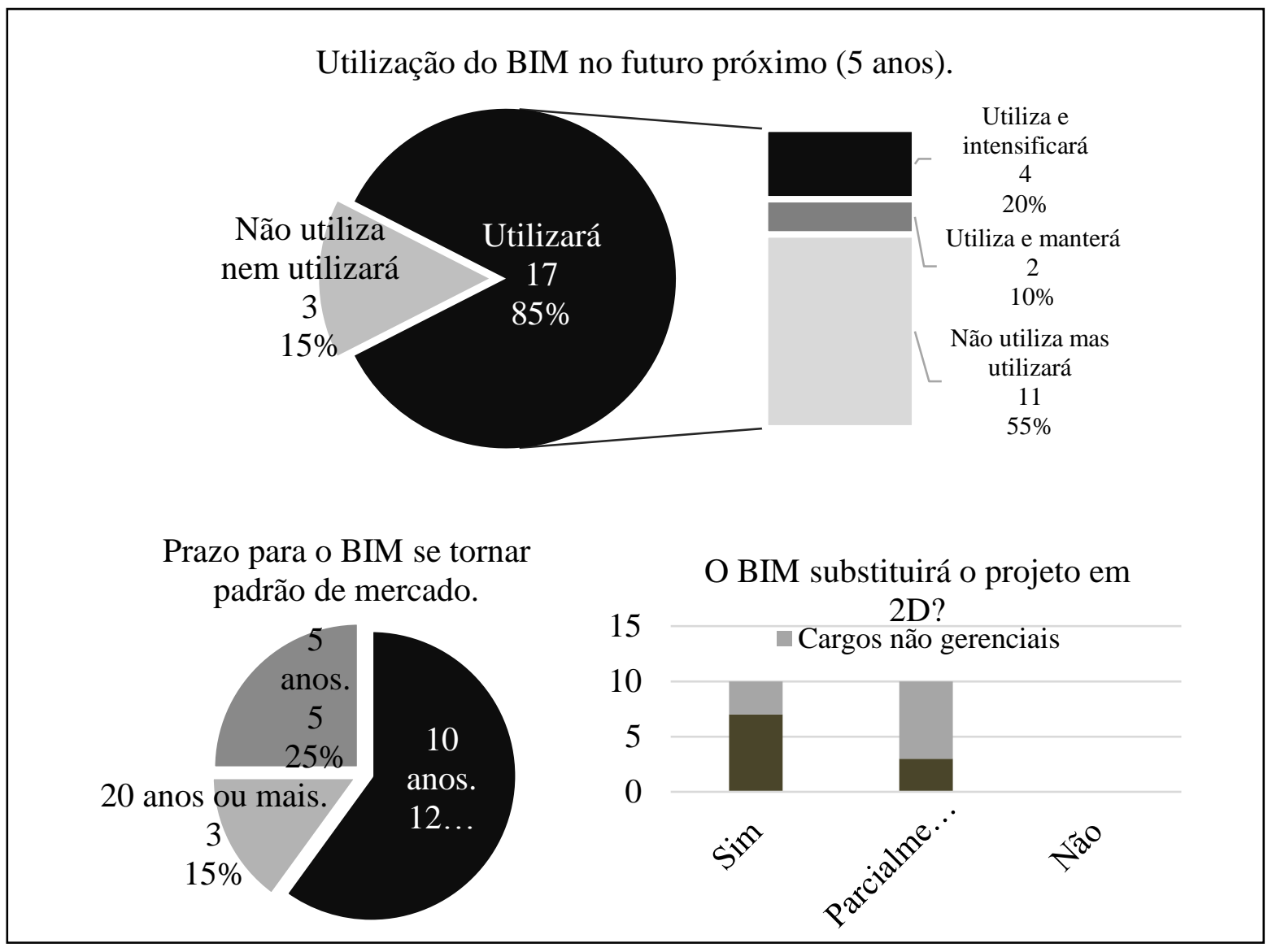

O impressionante avanço norte-americano em apenas três anos, apontado pela McGraw-Hill (2012), indica o Canadá e os Estados Unidos à frente da Finlândia, que é tida por muitos, em conjunto com outros países nórdicos, como um dos expoentes da adoção do BIM. No entanto, dados dessa mesma pesquisa demonstram que a difusão tecnológica não é uniforme, ao menos nos EUA, o que é reforçado pelo estudo de Langar e Pearce (2014). Esse tipo de constatação reforça a importância de uma maior segmentação das pesquisas quando se trata de países com extensões continentais.

\section{Principais aplicações}

Os dois principais usos do BIM pelas construtoras do Distrito Federal foram remoção de interferências e compatibilização de projetos, ambos com $63 \%$ das ocorrências. Essas utilizações ocuparam posições apenas intermediárias nas pesquisas de abrangência nacional e no sudeste estadunidense, sendo superadas por atividades voltadas à visualização e à execução de projetos (vide Tabela 7). Empregos mais complexos foram indicados por poucos usuários, seguindo a tendência de outros estudos. É possível que a predominância dessas atividades no Distrito Federal seja consequência da maneira como muitas das construtoras locais trabalham, exemplificada abaixo.

Uma incorporadora contrata um escritório de arquitetura para o desenvolvimento de um empreendimento. Em seguida, a equipe (ou empresa) construtora recebe o projeto arquitetônico para elaboração dos projetos complementares e construção. Cada disciplina de projeto (estrutura, hidráulica, elétrica, etc.) é encomendada a um projetista colaborador externo que confecciona isoladamente o projeto "executivo" de sua área de atuação. A construtora recebe esses diversos projetos e após uma árdua etapa de compatibilização e remoção de interferências obtém o projeto verdadeiramente executivo.

Partindo-se desse exemplo e observando os dados da Tabela 8, que indicam a terceirização de etapas fundamentais da aplicação da tecnologia (quando não a sua totalidade) por metade das construtoras que a adotam, não é de se estranhar que o BIM seja visto com um software de compatibilização de 
projetos, e seu uso se restrinja a atividades superficiais, enquadradas nos Estágios 1 e 2 de Succar (2010).

\section{Dificuldades de implantação}

Adotar o BIM não é fácil. Além do software e toda a infraestrutura de informática a ele atrelada, é necessário, dentre outras coisas, um corpo de profissionais qualificados para operar e coordenar as diversas frentes de projeto e processos envolvidos com a metodologia. Mas capacitar pessoas é um processo lento e caro e, provavelmente por isso, muitas empresas acabam por terceirizar os serviços que seriam executados por esses profissionais, como visto nos resultados da Tabela 8. Essa atitude reflete um comportamento imediatista e vai de encontro ao proposto pela literatura, pois acaba por burocratizar o fluxo de trabalho com a inserção de um novo personagem, muitas vezes posicionado entre os projetistas e aqueles que executarão os serviços, cuja função é converter projetos $2 \mathrm{D}$ em 3D. Esse cenário suscita uma série de questionamentos cujas respostas fogem ao escopo deste artigo, mas são extremamente relevantes: Quem é o responsável técnico pelo projeto? Quem responde por eventuais erros de projeto? Dúvidas devem ser encaminhadas ao projetista original ou ao profissional que converteu o projeto?

Das cinco principais dificuldades globais apontadas pelos respondentes (Tabela 10), apenas uma "O valor das licenças dos softwares" não está relacionada a recursos humanos. As outras quatro envolvem formação e capacitação de pessoas: "Desconhecimento/falta de informação sobre BIM; Falta de mão de obra interna especializada; Os arquitetos/projetistas colaboradores externos não utilizam BIM; Dificuldade de coordenação das diversas frentes de projeto e etapas envolvidas". Resultado semelhante foi encontrado por Malleson (2015) no Reino Unido, onde as duas maiores barreiras para implantação do BIM foram falta de mão de obra especializada e falta de treinamento (Tabela 5). Na pesquisa da Pini (2013), os maiores empecilhos foram os custos de aquisição, os custos de investimento em treinamentos e problemas com projetistas colaboradores.

A questão dos colaboradores e projetistas externos é, aparentemente, um item fundamental a ser resolvido para as construtoras do Distrito Federal. Ela foi a única dificuldade de implantação do BIM com prejuízo significativo para grandes empresas e, também, a única unanimidade dentre todas as segmentações, sendo considerada, ainda, muito prejudicial por ocupantes de cargos gerenciais e empresas de menor porte. Talvez esse item tenha sido ainda mais significativo para as pequenas empresas porque enquanto as grandes construtoras podem, teoricamente, escolher seus colaboradores e impor condições de trabalho, isso é muitas vezes impossível para as pequenas e médias. Há indícios, portanto, de que a adoção do BIM pelas construtoras seria facilitada caso os projetistas externos utilizassem a tecnologia, lembrando que o seu uso isolado não traz os maiores benefícios. Deve-se buscar o trabalho colaborativo, o que demanda uma profunda alteração nos processos e no modo de trabalho com o quais todos os envolvidos estão acostumados há anos.

$\mathrm{O}$ aspecto financeiro ganha importância à medida que se reduz o porte das organizações, conforme já esperado. Tulenheimo (2015) lembra que o custo do software não se limita à sua aquisição, pois há inúmeras atualizações e ferramentas não gratuitas que resultam em um valor adicional pago semestralmente da ordem de $5 \%$ a $20 \%$ daquele de aquisição. Há, ainda, uma grande variedade de tipos de licenças, desde unitárias até compartilhadas, que, dependendo da escolha, podem demandar uma estrutura administrativa e em rede para acessos e atualizações. Conforme já discutido, a capacitação é um processo dispendioso e a remuneração de profissionais qualificados tende a ser maior, algo relevante para orçamentos mais enxutos, e consequentemente mais prejudicial para as pequenas empresas. Percebe-se, portanto, que quanto menor é a organização, maiores são as dificuldades de adoção do BIM, mesmo entendimento das pesquisas de Langar e Pearce (2014) e da McGraw-Hill (2012).

Quando as respostas são analisadas levando-se em consideração as características pessoais dos respondentes, as maiores divergências surgem na percepção das dificuldades de implantação. Os profissionais que não utilizam BIM apontaram obstáculos no pouco conhecimento sobre a tecnologia, inclusive pelos líderes das organizações, e na falta de mão de obra especializada. Esses mesmos itens tiveram pouca importância para aqueles que utilizam o BIM, muito provavelmente isso pode ser atribuído ao fato de essas barreiras já terem caído nas empresas que usam a tecnologia.

Houve maiores diferenças entre as respostas de ocupantes de cargos gerenciais e não gerenciais, com os primeiros, no geral, atribuindo maiores importâncias às dificuldades enfrentadas, principalmente nos itens que envolvem administração de recursos, sejam eles humanos ou financeiros. O valor das licenças dos softwares, por exemplo, prejudicou muito a implantação do BIM para gerentes, enquanto na opinião dos outros, não. Esse resultado faz sentido quando se 
analisa o papel desempenhado por gestores que, dentre outras atividades, envolve a resolução de conflitos e a alocação de recursos, ao passo que projetistas, arquitetos e engenheiros têm funções mais operacionais.

\section{Resultado da utilização do BIM}

Apenas três das oito empresas afirmaram que o BIM trouxe resultados positivos, 37\%. É interessante notar que essas três construtoras têm o controle e a gestão de todos os processos envolvendo a tecnologia. Além disso, são duas delas que utilizam a tecnologia com maior profundidade - modelagem 4D, 5D, 6D e projeto colaborativo. Infere-se que os maiores benefícios do BIM só seriam percebidos por aqueles que imergem em suas ferramentas e alteram seus processos, conforme já discutido por outros autores (GROVER et al., 1998; AMOR; OWEN, 2011; MANZIONE et al., 2011).

\section{Futuro do BIM}

A grande maioria dos entrevistados, $85 \%$, acredita que utilizará o BIM nos próximos cinco anos, resultado em consonância com outras pesquisas: 90\% no Brasil; $92 \%$ na Finlândia; e 95\% no Reino Unido (PINI, 2013; FINNE; HAKKARAINEN; MALLESON, 2013; MALLESON, 2015). Esses resultados trazem esperança de que a tecnologia seja cada vez mais difundida, ao menos no Distrito Federal e nas demais regiões tratadas. Há, no entanto, uma ponderação a ser feita.

Os dados nacionais de 2013 apresentavam 38\% de adoção e $90 \%$ de expectativa de adoção dentro de cinco anos (PINI, 2013). A presente pesquisa, passados dois anos daquela, apresentou números ligeiramente inferiores para o Distrito Federal em ambos os aspectos, $36 \%$ e $85 \%$, respectivamente. Mas como não há (ao menos não foram encontrados) dados regionais anteriores, não se sabe se os valores aqui apresentados representam uma evolução local ou uma estagnação da tecnologia.

Enquanto $85 \%$ dos entrevistados se veem como usuários do BIM dentro de cinco anos, apenas $25 \%$ acredita que a tecnologia se torne o padrão de mercado no mesmo período. A maioria, $60 \%$, eleva esse prazo para dez anos e o restante, $15 \%$, para vinte anos ou mais. Quando indagados se o BIM, eventualmente, substituiria o projeto em 2D, houve uma divisão entre os respondentes, mas todos acreditam em uma substituição ao menos parcial. Os ocupantes de cargos gerenciais preveem uma mudança mais radical, sendo a maioria daqueles que acreditam na substituição total.

\section{Conclusão}

A utilização do BIM por construtoras no Distrito Federal é pequena e superficial, de acordo com os resultados apresentados. A sua comparação com os poucos dados nacionais disponíveis mostra que a adoção local é da mesma ordem de grandeza da média do País, com valores inferiores a $40 \%$ e piores que os cenários estrangeiros apresentados. Aparentemente pouco mudou nos dois anos que separam esses estudos tendo em vista a proximidade dos níveis de adoção apontados. Mas sem dados históricos e regionalizados não se pode afirmar se o BIM no Distrito Federal, dentro das condições de contorno estabelecidas, está estagnado ou evoluiu, alcançando a média nacional de 2013 .

Com base nas otimistas expectativas dos usuários quanto à utilização da tecnologia nos próximos cinco anos, presentes nesta pesquisa e naquela de âmbito nacional (PINI, 2013), e inspirando-se nas rápidas evoluções britânica e norte-americana, poder-se-ia concluir que o BIM tem um futuro promissor. Contudo, há que se observar que as dificuldades de implantação indicadas pelos respondentes são complexas e envolvem, em sua maioria, formação e capacitação de pessoas, o que normalmente é lento e dispendioso. Além disso, a utilização superficial da tecnologia e a manutenção do modo de trabalho empregado por muitas das construtoras locais podem fazer com que elas não se beneficiem de muitos dos possíveis resultados positivos decorrentes do BIM. Sem essa percepção de resultados, é possível que a implantação da tecnologia seja postergada, a cada ano, para o futuro próximo.

A repetição periódica deste tipo de pesquisa, com a criação de séries históricas, e a sua aplicação em outras localidades e regiões podem criar uma útil ferramenta de análise setorial, que pode trazer importantes informações que auxiliem na difusão do BIM, cujo potencial para a construção civil é, conforme já sabido, enorme.

\section{Referências}

\section{AGÊNCIA BRASILEIRA DE DESENVOLVIMENTO INDUSTRIAL.}

Relatório de Acompanhamento das Agendas Estratégicas Setoriais. Brasília, 2014.

AMOR, R; OWEN, R. Beyond BIM: it's not the end of the road! AECbytes Viewpoint, v. 58, 2011. 
ASSOCIAÇÃO BRASILEIRA DE NORMAS TÉCNICAS. NBR 15965-7: sistema de classificação da informação da construção: parte 7 . Rio de Janeiro, 2015.

ASSAF, S. A.; AL-HEJJI, S. Causes of Delay in Large Construction Projects. International Journal of Project Management, v. 24, n. 4, p. 349-357, 2006.

ASSAF, S. A.; AL-KHALIL, M.; AL-HAZMI, M. Causes of Delay in Large Building Construction Projects. Journal of Management in

Engineering, v. 11, n. 2, p. 45-50, 1995.

BIOTTO, C.; FORMOSO, C.; ISATTO, E. Método Para o Uso da Modelagem Bim 4d na Gestão da Produção em Empreendimentos de Construção. In: SIMPÓSIO BRASILEIRO DE QUALIDADE DO PROJETO NO AMBIENTE CONSTRUÍDO, 3., Campinas, 2013. Anais... Campinas, 2013.

BRASIL. Presidenta Dilma lança Plano Brasil Maior, nova política industrial do país.

Disponível em:

$<$ http://www2.planalto.gov.br/acompanhe-oplanalto/releases/presidenta-dilma-lanca-planobrasil-maior-nova-politica-industrial-do-pais>. Acesso em: 7 ago. 2017.

COMPANHIA DE PLANEJAMENTO DO DISTRITO FEDERAL. Brasília em Números. Disponível em <http://brasiliaemnumeros.codeplan.df.gov.br/mai n.html>. Acesso em: 20 jul. 2016.

\section{CONSELHO NACIONAL DE}

DESENVOLVIMENTO INDUSTRIAL. Agendas Estratégicas Setoriais - abril de 2013, Brasília., 2013. Disponível em:

<http://www.abdi.com.br/Acao Documento Legislacao/Agendas Estrat\%C3\%A9gicas Setoriais.pdf>

EASTMAN, C. et al. BIM Handbook a Guide to Building Information Modeling for Owners, Managers, Designers, Engineers, and Contractors. $2^{\text {nd }}$. ed. New Yiork: John Wiley \& Sons, 2011.

FINNE, C.; HAKKARAINEN, M.; MALLESON, A. Finnish BIM Survey 2013. 2013. Disponível em:

$<$ https://www.rakennustieto.fi/material/attachment s/tutkimus-

_ja_kehittamistoimita/6JKcTDSMO/BIM_Survey _Finland_findings.pdf>. Acesso em: 20 jul. 2016.
GARDEZI, S. S. S. et al. Challenges for Implementation of Building Information Modeling (BIM) in Malaysian Construction Industry. Applied Mechanics and Materials, v. 567, p. 559-564, jun. 2014.

GROVER, V. et al. The Influence of Information Technology Diffusion and Business Process Change on Perceived Productivity: the IS Executive's perspective. Information Management Journal, v. 34, p. 141-159, 1998.

HAYMAKER, J.; FISCHER, M. Challenges and Benefits of 4D Modeling on the Walt Disney Concert Hall Project. CIFE TWorking Paper: WP 64, Stanford University, p. 1-17, jan. 2001.

KAZAZ, A.; ULUBEYLI, S.; TUNCBILEKLI, N. A. Causes of Delays in Construction Projects in Turkey. Journal of Civil Engineering and Management, v. 18, n. 3, p. 426-435, 2012.

LANGAR, S.; PEARCE, A. State of Adoption for Building Information Modeling (BIM) in the Southeastern United States. In: ASC ANNUAL INTERNATIONAL CONFERENCE PROCEEDINGS, 50., Washington, 2014. Proceedings... Washington, 2014.

LINDBLAD, H. Study of the Implementation Process of BIM in Construction Projects. Master Thesis - Department of Real Estate and Construction Management, Stockholm, 2013.

MALLESON, A. BIM Survey: summary of findings. NBS National BIM Report 2015, p. 8$17,2015$.

MANZIONE, L. et al. Desafios Para a Implementação do Processo de Projeto Colaborativo: análise do fator humano. In: ENCONTRO DE TECNOLOGIA DE INFORMAÇÃO E COMUNICAÇÃO NA CONSTRUÇÃO, 5., Salvador, 2011. Anais... Salvador, 2011.

MCGRAW-HILL CONSTRUCTION. The Business Value of BIM in North-America: MultiYear Trend Analysis and User Ratings (20072012). SmartMarket Report, p. 7-14, 2012.

MIETTINEN, R.; PAAVOLA, S. Beyond the BIM utopia: approaches to the development and implementation of building information modeling. Automation in Construction, v. 43, p. 84-91, 2014.

PINI. Pesquisa Mostra que Mais de $90 \%$ dos Arquitetos e Engenheiros Pretendem Utilizar o BIM em Até Cinco Anos. 2013. Disponível em: $<$ http://piniweb.pini.com.br/construcao/carreiraexercicio-profissional-entidades/pesquisa-mostraque-mais-de-90-dos-arquitetos-e-engenheiros291885-1.aspx>. Acesso em: 29 mar. 2016. 
REKOLA, M.; KOJIMA, J.; MÄKELÄINEN, T. Towards Integrated Design and Delivery Solutions: pinpointed challenges of process change. Architectural Engineering and Design Management, v. 6, n. 4, p. 264-278, 2010.

SACKS, A. R. Building Information Modeling Support for Production Control On Site, Advanced BIM Seminar - SECOVI, 2011. Disponível em: <http://site.abece.com.br/download/pdf/Palestra_R afaelSacks.pdf>. Acesso em: 10 ago. 2017.

SERVIÇO BRASILEIRO DE APOIO ÀS MICRO E PEQUENAS EMPRESAS. Critérios de Classificação de Empresas. Disponível em: $<$ http://www.sebrae-

sc.com.br/leis/default.asp?vcdtexto=4154>. Acesso em: 30 jun. 2015.
SUCCAR, B. Building Information Modelling Maturity Matrix. In: UNDERWOOD, J.; ISIKDAG, U. (Eds.). Handbook of Research on Building Information Modelling and Construction Informatics: concepts and technologies. Hershey: IGI Publishing, 2010.

TULENHEIMO, R. Challenges of Implementing New Technologies in the World of BIM: case study from construction engineering industry in Finland. Procedia Economics and Finance, v. 21, n. Henttinen, p. 469-477, 2015.

VIVANCOS, A. Estruturas Organizacionais de Empresas Construtoras de Edifícios em Processo de Implementação de Sistemas de Gestão da Qualidade. São Paulo, 2001.

Dissertação (Mestrado em Engenharia Civil) Escola de Engenharia, Universidade de São Paulo, São Paulo, 2001.

Revista Ambiente Construído

Associação Nacional de Tecnologia do Ambiente Construído

Av. Osvaldo Aranha, $99-3^{\circ}$ andar, Centro

Porto Alegre - RS - Brasil CEP $90035-190$

Telefone: +55 (51) 3308-4084

Fax: +55 (51) 3308-4054

www.seer.ufrgs.br/ambienteconstruido

E-mail: ambienteconstruido@ufrgs.br 